Article

\title{
Effects of $\mathrm{HfB}_{2}$ and $\mathrm{HfN}$ Additions on the Microstructures and Mechanical Properties of $\mathrm{TiB}_{2}$-Based Ceramic Tool Materials
}

\author{
Jing An ${ }^{1,2}$, Jinpeng Song ${ }^{1,2, *}$, Guoxing Liang ${ }^{1,2}$, Jiaojiao Gao ${ }^{1,2}$, Juncai Xie ${ }^{1,2}$, Lei Cao ${ }^{1,2}$, \\ Shiying Wang ${ }^{1,2}$ and Ming Lv ${ }^{1,2}$ \\ 1 School of Mechanical Engineering, Taiyuan University of Technology, Taiyuan 030024, China; \\ anjing@tyut.edu.cn (J.A.); liangguoxing@tyut.edu.cn (G.L.); gaojiaojiao1207@163.com (J.G.); \\ 15834068972@163.com (J.X.); 17603410780@163.com (L.C.); wangshiying@tyut.edu.cn (S.W.); \\ lvming@tyut.edu.cn (M.L.) \\ 2 Shanxi Key Laboratory of Precision Machining, The Shanxi Science and Technology Department, \\ Taiyuan University of Technology, Taiyuan 030024, China \\ * Correspondence: songjinpeng@tyut.edu.cn
}

Academic Editor: Dinesh Agrawal

Received: 23 March 2017; Accepted: 25 April 2017; Published: 27 April 2017

\begin{abstract}
The effects of $\mathrm{HfB}_{2}$ and $\mathrm{HfN}$ additions on the microstructures and mechanical properties of $\mathrm{TiB}_{2}$-based ceramic tool materials were investigated. The results showed that the $\mathrm{HfB}_{2}$ additive not only can inhibit the $\mathrm{TiB}_{2}$ grain growth but can also change the morphology of some $\mathrm{TiB}_{2}$ grains from bigger polygons to smaller polygons or longer ovals that are advantageous for forming a relatively fine microstructure, and that the HfN additive had a tendency toward agglomeration. The improvement of flexural strength and Vickers hardness of the $\mathrm{TiB}_{2}-\mathrm{HfB}_{2}$ ceramics was due to the relatively fine microstructure; the decrease of fracture toughness was ascribed to the formation of a weaker grain boundary strength due to the brittle rim phase and the poor wettability between $\mathrm{HfB}_{2}$ and $\mathrm{Ni}$. The decrease of the flexural strength and Vickers hardness of the $\mathrm{TiB}_{2}-\mathrm{HfN}$ ceramics was due to the increase of defects such as $\mathrm{TiB}_{2}$ coarse grains and HfN agglomeration; the enhancement of fracture toughness was mainly attributed to the decrease of the pore number and the increase of the rim phase and $\mathrm{TiB}_{2}$ coarse grains. The toughening mechanisms of $\mathrm{TiB}_{2}-\mathrm{HfB}_{2}$ ceramics mainly included crack bridging and transgranular fracture, while the toughening mechanisms of $\mathrm{TiB}_{2}-\mathrm{HfN}$ ceramics mainly included crack deflection, crack bridging, transgranular fracture, and the core-rim structure.
\end{abstract}

Keywords: $\mathrm{TiB}_{2}-\mathrm{HfB}_{2}$ ceramics; $\mathrm{TiB}_{2}-\mathrm{HfN}$ ceramics; hot-pressed sintering; microstructure; mechanical properties

\section{Introduction}

In recent years, with the widespread use of difficult-to-machine materials in engineering, cutting tools have faced the challenge of machining these materials under high speed, which requires that the tools have high hardness, excellent wear resistance, oxidation resistance, and so on. However, compared with the ceramic tool materials, the traditional tool materials (high-speed steel and cemented carbide) showed a lower red hardness in machining these difficult-to-machine materials, which did not meet the need of high speed machining. Recently, ceramic tools- $\mathrm{Al}_{2} \mathrm{O}_{3}$-based, $\mathrm{Si}_{3} \mathrm{~N}_{4}$-based, and $\mathrm{TiB}_{2}$-based ceramic tools-exhibited excellent cutting performance in machining the difficult-to-machine materials such as martensitic stainless steel, Inconel 718, ultra-high-strength steel $300 \mathrm{M}$, heat-treated AISI4140, hardened Cr12MoV mold steel, and Invar36 alloy [1-6]. The TiB 2 -based ceramic tool exhibited higher hardness compared with the other ceramic tools, which was attributed 
to the higher hardness of $\mathrm{TiB}_{2}$ ceramic than that of the other ceramics. $\mathrm{TiB}_{2}$ also has a high melting point, excellent wear resistance, and oxidation resistance, which can also be applied in other fields such as manufacturing armor plates and dies [7-10]. However, it shows a tendency toward low flexural strength and low fracture toughness, which limits the more widespread application of $\mathrm{TiB}_{2}$. In order to reverse this tendency and improve the mechanical properties of $\mathrm{TiB}_{2}$ ceramic, reinforcements such as hard phases, metal phases, and whiskers have been employed to fabricate $\mathrm{TiB}_{2}$-based ceramic materials through spark plasma sintering, vacuum hot-pressed sintering, or reactive hot-pressed sintering.

Usually, the hard phases included $\mathrm{TaC}, \mathrm{TiSi}_{2}, \mathrm{Al}_{2} \mathrm{O}_{3}, \mathrm{WC}, \mathrm{TiC}, \mathrm{B}_{4} \mathrm{C}, \mathrm{NbC}, \mathrm{MoSi}_{2}, \mathrm{SiC}$, and $\mathrm{ZrB}_{2}$ [9-16], which could inhibit the grain growth of the base material to obtain a fine microstructure. $\mathrm{HfB}_{2}$ and $\mathrm{HfN}$ have high hardness, high melting point, and high oxidation resistance, and as reinforcements they can enhance the mechanical properties of ceramics such as $\mathrm{ZrB}_{2}-\mathrm{CrSi}_{2}-\mathrm{HfB}_{2}, \mathrm{ZrB}_{2}-\mathrm{SiC}-\mathrm{HfB}_{2}, \mathrm{~B}_{4} \mathrm{C}-\mathrm{HfB}_{2}$, and $\mathrm{SiBCN}-\mathrm{HfN}$ [17-20], which make them potential candidate reinforcements for ceramic tool materials. In addition, because $\mathrm{HfB}_{2}$ and $\mathrm{HfN}$ have better thermal stability to resist deformation and decomposition at elevated temperature, they may improve the cutting performance and working life of $\mathrm{TiB}_{2}$-based ceramic tools. The metal phases often contain $\mathrm{Fe}, \mathrm{Co}, \mathrm{Ni}$, and $\mathrm{Mo}[7,12,21,22]$, which could decrease the sintering temperature and improve the boundary strength among grains and relative density, while the ceramic whiskers such as aluminum borate whiskers and $\mathrm{SiC}$ whiskers could change the direction of crack growth to consume more crack propagation energy [23-25], which could improve the flexural strength and fracture toughness. Usually, adopting a combination of reinforcements for fabricating $\mathrm{TiB}_{2}$-based ceramics can obtain better mechanical properties. In addition, compared with spark plasma sintering that is employed in fabricating the ceramic composites $[9,16]$, vacuum hot-pressed sintering is considered to be easily adaptable and economically viable.

In this paper, $\mathrm{TiB}_{2}-\mathrm{HfB}_{2}$ and $\mathrm{TiB}_{2}-\mathrm{HfN}$ ceramic tool materials will be fabricated with powders of $\mathrm{TiB}_{2}, \mathrm{HfB}_{2}, \mathrm{HfN}$, Mo, and Ni by vacuum hot-pressed sintering. The characteristics of these composites are analyzed according to their microstructures and mechanical properties.

\section{Experimental Procedures}

Commercially available $\mathrm{TiB}_{2}$ powder $(99.9 \%, 1 \mu \mathrm{m}$, Shanghai Xiangtian Nanomaterials Co., Ltd., Shanghai, China), $\mathrm{HfB}_{2}$ powder $(99.9 \%, 0.8 \mu \mathrm{m}$, Shanghai Chaowei Nanomaterials Co., Ltd., Shanghai, China) and HfN powder $(99.9 \%, 0.8 \mu \mathrm{m}$, Shanghai Chaowei Nanomaterials Co., Ltd.) were used as the raw materials. Ni powder $(99.8 \%, 1 \mu \mathrm{m}$, Shanghai Yunfu Nanotechnology Co., Ltd., Shanghai, China) and Mo powder (99.8\%, $1 \mu \mathrm{m}$, Shanghai Yunfu Nanotechnology Co., Ltd.) were added as sintering aids. The compositions of the composite tool materials are shown in Table 1.

Table 1. Compositions of $\mathrm{TiB}_{2}-\mathrm{HfB}_{2}$ and $\mathrm{TiB}_{2}-\mathrm{HfN}$ ceramic tool materials.

\begin{tabular}{cccccc}
\hline Sample & $\mathbf{T i B}_{\mathbf{2}} / \mathbf{w t} \%$ & $\mathbf{H f B}_{\mathbf{2}} / \mathbf{w t} \%$ & $\mathbf{H f N} / \mathbf{w t} \%$ & $\mathbf{N i} / \mathbf{w t} \%$ & $\mathbf{M o} / \mathbf{w t} \%$ \\
\hline S1 & 82 & 10 & - & 4 & 4 \\
S2 & 72 & 20 & - & 4 & 4 \\
S3 & 62 & 30 & - & 4 & 4 \\
S4 & 82 & - & 10 & 4 & 4 \\
S5 & 72 & - & 20 & 4 & 4 \\
S6 & 62 & - & 30 & 4 & 4 \\
\hline
\end{tabular}


The powders were mixed and milled for $48 \mathrm{~h}$ in a polyethylene jar with WC (tungsten carbide) balls and alcohol as the medium. Then the mixed slurry was dried in vacuum and sieved by a 200-mesh sieve. The compacted powders were hot pressed for $30 \mathrm{~min}$ at $1650{ }^{\circ} \mathrm{C}$ under $30 \mathrm{MPa}$ in a vacuum $\left((1.2-2.4) \times 10^{-3} \mathrm{~Pa}\right)$. The hot pressed samples were cut into testing specimens by the electrical discharge wire cutting method and the surfaces of the testing bars were polished using diamond slurries. The dimensions of the specimens were $3 \mathrm{~mm} \times 4 \mathrm{~mm} \times 40 \mathrm{~mm}$.

Flexural strength was measured at a span of $30 \mathrm{~mm}$ and a crosshead speed of $0.5 \mathrm{~mm} / \mathrm{min}$ by the three-point bending test method on an electron universal tester (CREE-8003G, Dongguan City Kerry Instrument Technology Co., Ltd., Dongguan, China), according to Chinese National Standards GB/T 6569-2006/ISO 14704:2000 [26]. The fracture toughness $\left(K_{I C}\right)$ was measured via the direct indentation method and was calculated through the following equation $[12,27]$ :

$$
K_{I C}=0.203 H_{V} a^{1 / 2}\left(\frac{c}{a}\right)^{-3 / 2}
$$

where $H_{V}$ is the Vickers hardness, $2 a$ is the length of the impression diagonal, and $2 c$ is the overall indentation crack length including $2 a$. The indenter (HVS-30, Shanghai Precision Instruments Co., Ltd., Shanghai, China) was of Vickers DPH (diamond pyramid hardness) type and the applied static load was $196 \mathrm{~N}$ for $15 \mathrm{~s}$. Vickers hardness was measured on the polished surfaces using a diamond pyramid indenter under a load of $196 \mathrm{~N}$ by an HV-120 based on Chinese National Standards GB/T 16534-2009 [28]. The relative density of each specimen was measured by the Archimedes method with distilled water as the medium. The theoretical density was calculated according to the rule of mixtures based on the following densities: $4.52,10.50,13.80,8.90$, and $10.20 \mathrm{~g} / \mathrm{cm}^{3}$ for $\mathrm{TiB}_{2}, \mathrm{HfB}_{2}$, $\mathrm{HfN}, \mathrm{Ni}$, and Mo, respectively. At least 15 specimens were tested for each experimental condition. X-ray diffraction (XRD, EMPYREAN, PANalytical B.V., Almelo, Netherlands) and energy dispersive spectrometry (EDS, ACT-350, Oxford Instruments, Oxford, UK) were used to analyze the compositions of the composite. Scanning electron microscopy and back scattered electron microscopy (SEM, BSE, Supra-55, Carl Zeiss AG, Oberkochen, Germany) were used to observe the polished surface and fractured surface morphologies.

\section{Results and Discussions}

\subsection{Microstructure}

Figure 1 shows the $\mathrm{XRD}$ patterns of the $\mathrm{TiB}_{2}-\mathrm{HfB}_{2}$ and $\mathrm{TiB}_{2}-\mathrm{HfN}$ ceramic tool materials. The major crystal phases are $\mathrm{TiB}_{2}$ and $\mathrm{HfB}_{2}$ in the $\mathrm{TiB}_{2}-\mathrm{HfB}_{2}$ ceramics, and $\mathrm{TiB}_{2}$ and $\mathrm{HfN}$ in the $\mathrm{TiB}_{2}$-HfN ceramics. The minor phase is the $\mathrm{Ni}_{3} \mathrm{Mo}$ intermetallic compound in the $\mathrm{TiB}_{2}-\mathrm{HfB}_{2}$ and $\mathrm{TiB}_{2}-\mathrm{HfN}$ ceramic tool materials. This is because $\mathrm{Ni}$ and Mo can form the $\mathrm{Ni}_{3} \mathrm{Mo}$ intermetallic compound at $1300{ }^{\circ} \mathrm{C}$ [29]. The $\mathrm{Ni}_{3}$ Mo intermetallic compound has a high melting point of about $1320{ }^{\circ} \mathrm{C}$, so it may be a promising high-temperature structural material [30]. Compared with the standard peaks, the peaks of $\mathrm{HfB}_{2}$ are offset about two degrees to the right and are near the peaks of $\mathrm{TiB}_{2}$. This indicates there is likely an exchange of Ti and Hf atoms in the sintering, which leads to a complex solid solution of $\mathrm{TiB}_{2}$ and $\mathrm{HfB}_{2}$ formed in the ceramic tool materials. The peaks of HfN are in accordance with the standard peaks. 


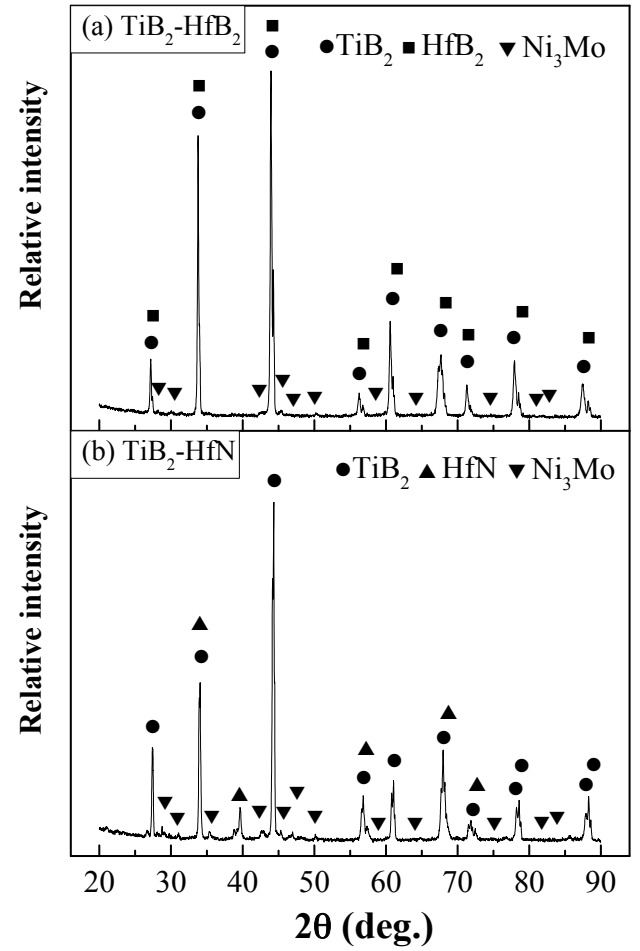

Figure 1. $\mathrm{XRD}$ patterns of $\mathrm{TiB}_{2}-\mathrm{HfB}_{2}$ and $\mathrm{TiB}_{2}-\mathrm{HfN}$ ceramic tool materials.

SEM-BSE photographs of the polished surfaces of the $\mathrm{TiB}_{2}-\mathrm{HfB}_{2}$ and $\mathrm{TiB}_{2}-\mathrm{HfN}$ ceramic tool materials are presented in Figure 2. An obvious difference between the $\mathrm{TiB}_{2}-\mathrm{HfB}_{2}$ and $\mathrm{TiB}_{2}-\mathrm{HfN}$ ceramics is the presence of two phases (dark phase and white phase) in Figure $2 \mathrm{a}-\mathrm{c}$, while there are three phases (dark phase, white phase, and grey phase) in Figure $2 \mathrm{~d}-\mathrm{f}$. The dark phase in Figure 2a- $\mathrm{f}$ is $\mathrm{TiB}_{2}$ based on the XRD and EDS results in Figures $3 \mathrm{a}$ and $3 \mathrm{c}$. The white phase in Figure $2 \mathrm{a}-\mathrm{c}$ is mainly $\mathrm{HfB}_{2}$ according to the XRD and EDS results in Figure $3 b$, while the white phase in Figure $2 \mathrm{~d}-\mathrm{f}$ is mainly HfN according to the XRD and EDS results in Figure $3 \mathrm{~d}$. The grey phase in Figure $2 \mathrm{~d}-\mathrm{f}$ consists of $\mathrm{TiB}_{2}$ and $\mathrm{HFN}$ based on the XRD and EDS results in Figure 3e. Ni and Mo were also discovered in the EDS results in Figure 3. It is notable that the typical core-rim structures and pores exist in these ceramics as shown in Figure 2. The cores-the $\mathrm{TiB}_{2}$ grains-are wrapped by the rims. The rim phase in Figure $2 \mathrm{a}-\mathrm{c}$ is composed of the $\mathrm{Ni}_{3} \mathrm{Mo}$ intermetallic compound and the complex solid solution of $\mathrm{HfB}_{2}$ and $\mathrm{TiB}_{2}$. However, the rim phase in Figure $2 \mathrm{~d}-\mathrm{f}$ is composed of the $\mathrm{Ni}_{3} \mathrm{Mo}$ intermetallic compound and the potential complex solid solution of $\mathrm{HfN}$ and $\mathrm{TiB}_{2}$. Moreover, in the $\mathrm{TiB}_{2}-\mathrm{HfB}_{2}$ ceramics, the rim phase (the complex solid solution of $\mathrm{HfB}_{2}$ and $\mathrm{TiB}_{2}$ ) gradually occupies a leading position as the $\mathrm{HfB}_{2}$ content increases. The number of pores decrease slightly in Figure $2 a-c$, but increase gradually in Figure $2 \mathrm{~d}-\mathrm{f}$. In terms of size and shape, the pores in Figure 2a-c are bigger than that in Figure $2 \mathrm{~d}-\mathrm{f}$; the regular pore shape in Figure $2 \mathrm{a}-\mathrm{c}$ looks like the $\mathrm{TiB}_{2}$ grain shape and the irregular pore shape in Figure $2 \mathrm{~d}-\mathrm{f}$ looks like the shape of agglomerated HfN grains possibly pulled out in the grinding and polishing process, which indicates that a weaker grain boundary strength formed in these ceramics in the sintering processing. Moreover, in Figure $2 \mathrm{a}-\mathrm{c}$ the morphology of some $\mathrm{TiB}_{2}$ grains changes from bigger polygons to smaller polygons or longer ovals which is advantageous for the formation of a relatively fine microstructure, and in Figure $2 \mathrm{~d}-\mathrm{f}$ the $\mathrm{HfN}$ grain agglomeration becomes more serious leading to the formation of more $\mathrm{TiB}_{2}$ coarse grains and pores. This indicates that the $\mathrm{HfB}_{2}$ additive not only can inhibit the growth of $\mathrm{TiB}_{2}$ grains but can also change the morphology of some $\mathrm{TiB}_{2}$ grains, and that the HfN additive exhibits a tendency toward agglomeration. 

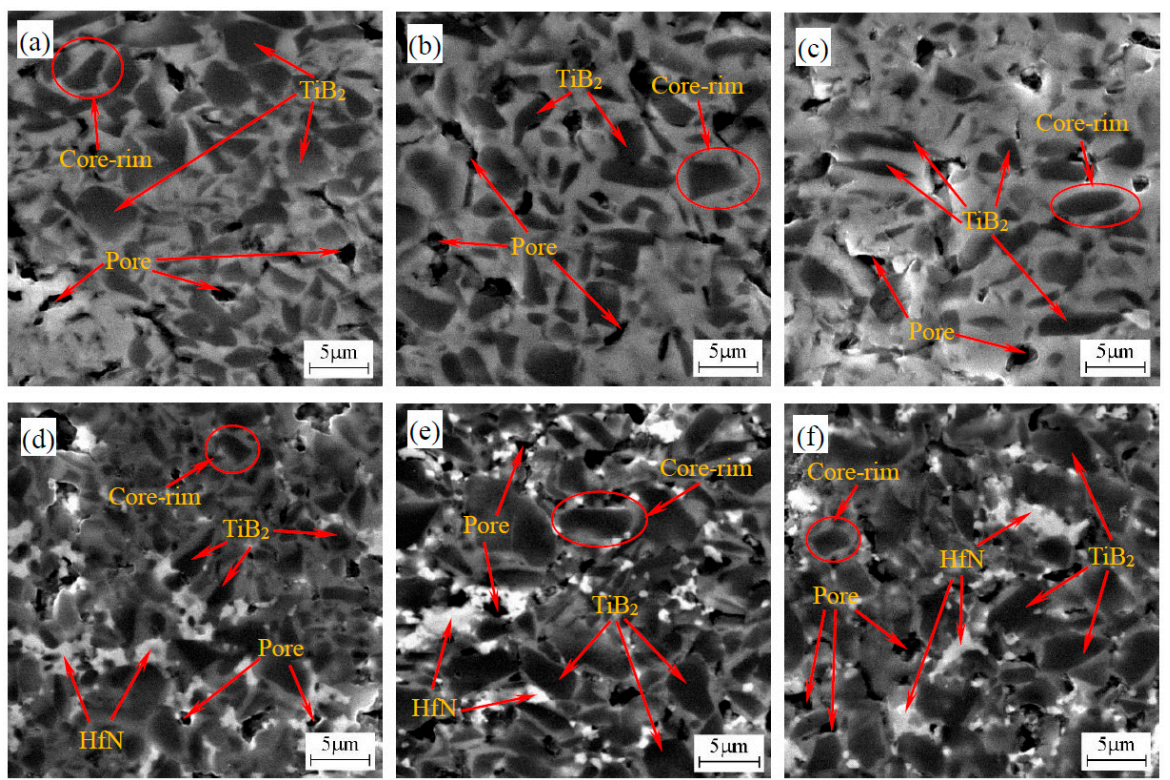

Figure 2. SEM-BSE photographs of the polished surfaces of $\mathrm{TiB}_{2}-\mathrm{HfB}_{2}$ and $\mathrm{TiB}_{2}-\mathrm{HfN}$ ceramic tool materials: (a) $\mathrm{TiB}_{2}-10$ wt $\% \mathrm{HfB}_{2}$; (b) $\mathrm{TiB}_{2}-20$ wt $\% \mathrm{HfB}_{2}$; (c) $\mathrm{TiB}_{2}-30$ wt $\% \mathrm{HfB}_{2}$; (d) $\mathrm{TiB}_{2}-10$ wt \% HfN; (e) $\mathrm{TiB}_{2}-20$ wt \% HfN; (f) $\mathrm{TiB}_{2}-30$ wt \% HfN.
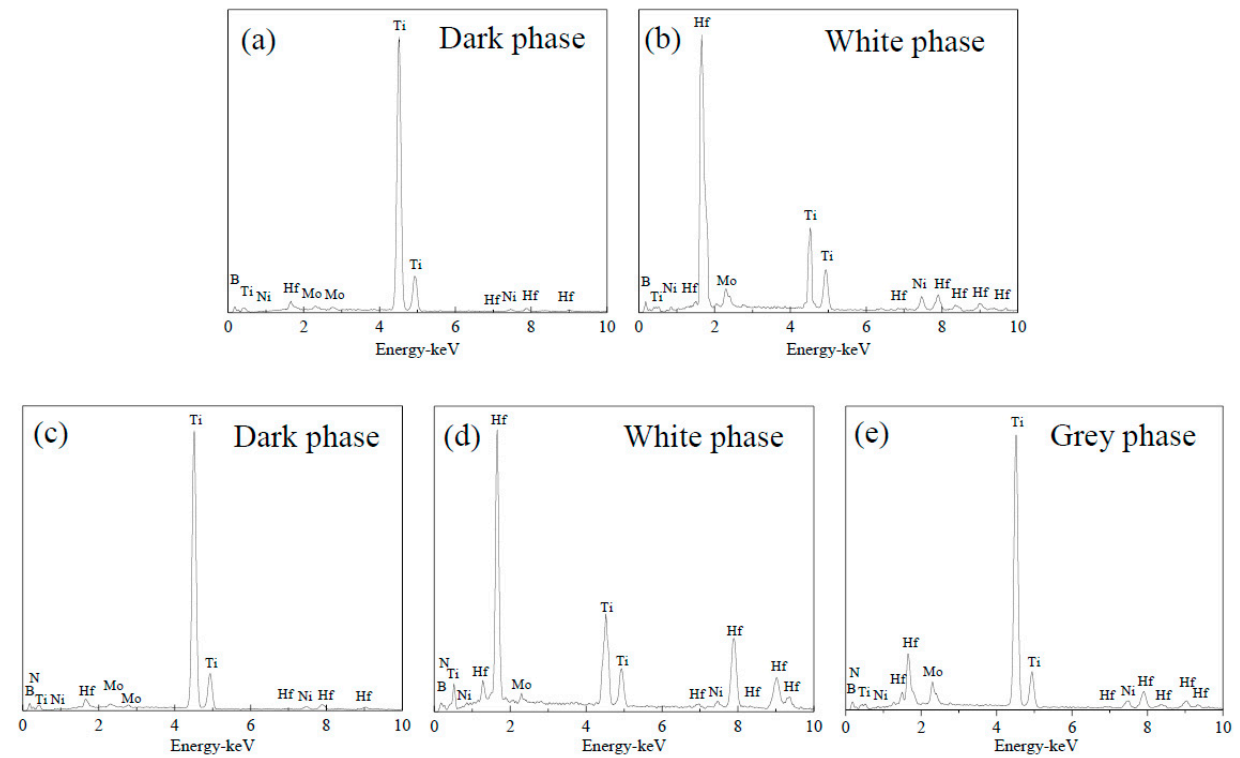

Figure 3. EDS of the phases in the $\mathrm{TiB}_{2}-\mathrm{HfB}_{2}$ ceramic tool materials: (a) EDS of the dark phase; (b) EDS of the white phase, and EDS of the phases in the $\mathrm{TiB}_{2}-\mathrm{HfN}$ ceramic tool materials; (c) EDS of the dark phase; (d) EDS of the white phase; (e) EDS of the grey phase.

Figure 4 shows the fracture morphology of the $\mathrm{TiB}_{2}-\mathrm{HfB}_{2}$ and $\mathrm{TiB}_{2}-\mathrm{HfN}$ ceramic tool materials. As can be seen in Figure $4 \mathrm{a}-\mathrm{c}$, with increasing $\mathrm{HfB}_{2}$ content from $10 \mathrm{wt} \%$ to $30 \mathrm{wt} \%$, the $\mathrm{TiB}_{2}$ grains become smaller; meanwhile, the $\mathrm{TiB}_{2}$ grain shapes exhibit the same variation trend as presented in Figure 3a-c; moreover, the pore number decreases progressively. However, in Figure $4 \mathrm{~d}-\mathrm{f}$ with increasing $\mathrm{HfN}$ content from $10 \mathrm{wt} \%$ to $30 \mathrm{wt} \%$, the $\mathrm{TiB}_{2}$ grains become larger leading to the formation of coarse $\mathrm{TiB}_{2}$ grains; and the pore number decreases progressively. The results indicate that the $\mathrm{HfB}_{2}$ additive can not only inhibit the growth of the $\mathrm{TiB}_{2}$ grains, but can also change the microstructure of $\mathrm{TiB}_{2}$-based ceramic, and that the $\mathrm{HfN}$ additive cannot inhibit the $\mathrm{TiB}_{2}$ grain growth. 

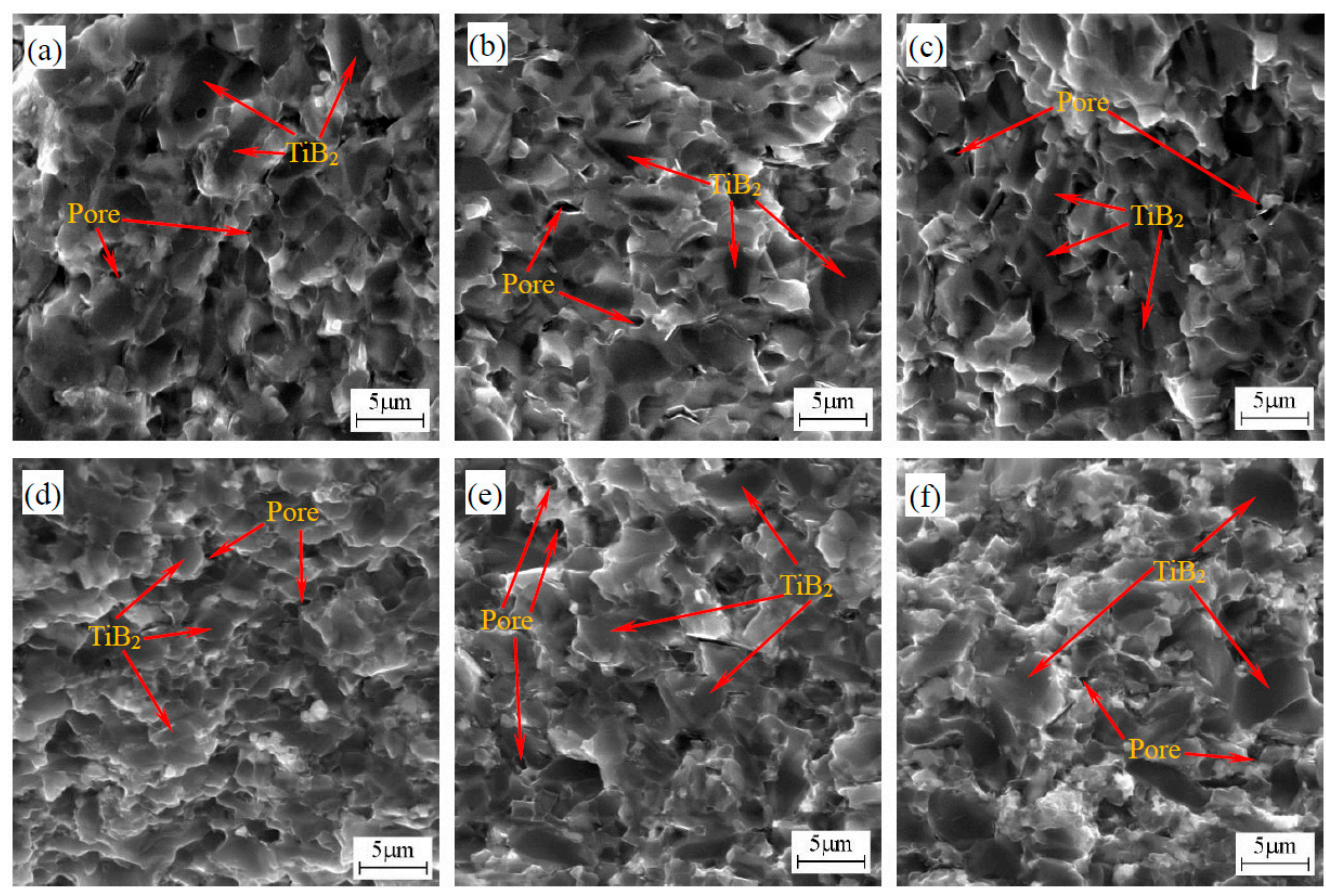

Figure 4. Fracture morphology of $\mathrm{TiB}_{2}-\mathrm{HfB}_{2}$ and $\mathrm{TiB}_{2}-\mathrm{HfN}$ ceramic tool materials: (a) $\mathrm{TiB}_{2}-10$ wt $\%$ $\mathrm{HfB}_{2}$; (b) $\mathrm{TiB}_{2}-20$ wt \% $\mathrm{HfB}_{2}$; (c) $\mathrm{TiB}_{2}-30$ wt $\% \mathrm{HfB}_{2}$; (d) $\mathrm{TiB}_{2}-10$ wt \% HfN; (e) $\mathrm{TiB}_{2}-20$ wt \% HfN; (f) $\mathrm{TiB}_{2}-30 \mathrm{wt} \% \mathrm{HfN}$.

Figure 5 presents the relative densities of the $\mathrm{TiB}_{2}-\mathrm{HfB}_{2}$ and $\mathrm{TiB}_{2}-\mathrm{HfN}$ ceramic tool materials. As can be seen, their relative densities increase with increasing $\mathrm{HfB}_{2}$ and $\mathrm{HfN}$ contents from $10 \mathrm{wt} \%$ to $30 \mathrm{wt} \%$, respectively. The relative density increments of the $\mathrm{TiB}_{2}-\mathrm{HfN}$ ceramics are smaller, and the relative density variation curve is relatively flat, while the relative density variation curve of $\mathrm{TiB}_{2}-\mathrm{HfB}_{2}$ shows a bigger increment in relative density at first, and then finally shows a smaller increment. These results are ascribed to the pore number reduction with increasing the additive content, to some extent, and is derived from the higher sintering pressure ( $30 \mathrm{MPa})$ and the metal phases ( $\mathrm{Ni}$ and $\mathrm{Mo}$ ) that can efficiently reduce the sintering temperature and can accelerate the densification of these ceramics. As a consequence, their relative densities with the addition of $\mathrm{HfB}_{2}$ or $\mathrm{HfN}$ can be improved, and when the $\mathrm{HfB}_{2}$ and $\mathrm{HfN}$ contents are $30 \mathrm{wt} \%$, the optimal relative densities of the $\mathrm{TiB}_{2}-\mathrm{HfB}_{2}$ and $\mathrm{TiB}_{2}$-HfN ceramics are $99.0 \% \pm 0.2 \%$ and $99.4 \% \pm 0.3 \%$, respectively.

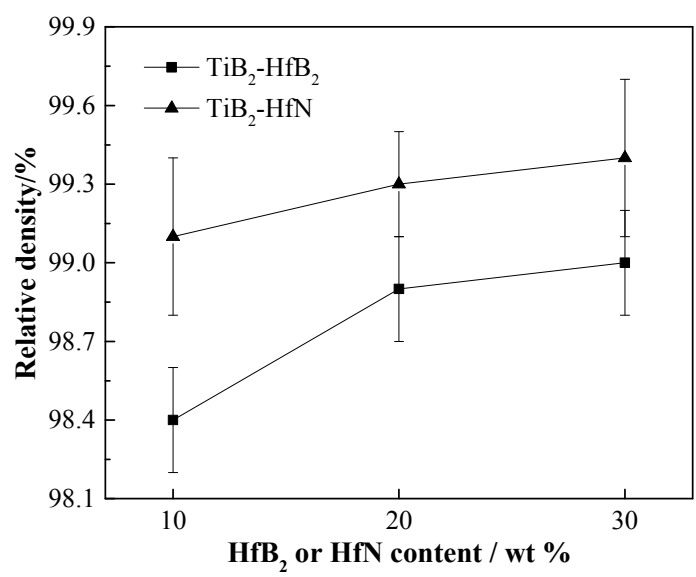

Figure 5. Relative densities of $\mathrm{TiB}_{2}-\mathrm{HfB}_{2}$ and $\mathrm{TiB}_{2}-\mathrm{HfN}$ ceramic tool materials. 


\subsection{Mechanical Properties}

Figure 6 exhibits the variation of the mechanical properties of the $\mathrm{TiB}_{2}-\mathrm{HfB}_{2}$ ceramics with changes of the $\mathrm{HfB}_{2}$ content and variation of the mechanical properties of the $\mathrm{TiB}_{2}-\mathrm{HfN}$ ceramics with changes of the HfN content. In Figure 6a, with the increase of the $\mathrm{HfB}_{2}$ content from 10 wt $\%$ to $30 \mathrm{wt} \%$, the flexural strength increases from $680.49 \pm 15 \mathrm{MPa}$ to $708.71 \pm 18 \mathrm{MPa}$; Vickers hardness increases from $19.15 \pm 0.21 \mathrm{GPa}$ to $21.52 \pm 0.24 \mathrm{GPa}$; however, the fracture toughness decreases from $6.92 \pm 0.18 \mathrm{MPa} \cdot \mathrm{m}^{1 / 2}$ to $5.53 \pm 0.18 \mathrm{MPa} \cdot \mathrm{m}^{1 / 2}$. The $\mathrm{TiB}_{2}-30$ wt $\% \mathrm{HfB}_{2}$ ceramic tool material exhibits better mechanical properties including flexural strength of $708.71 \pm 18 \mathrm{MPa}$, which is higher than $533 \mathrm{MPa}$ (the flexural strength of $\mathrm{TiB}_{2}-\mathrm{TaC}$ ceramics [9]), Vickers hardness of $21.52 \pm 0.24 \mathrm{GPa}$ that is higher than $19.8 \pm 0.6 \mathrm{GPa}$ (Vickers hardness of the $\mathrm{TiB}_{2}-\mathrm{SiC}-\mathrm{CNTs}$ ceramics [8]), and fracture toughness of $5.53 \pm 0.18 \mathrm{MPa} \cdot \mathrm{m}^{1 / 2}$ that is higher than $5.2 \mathrm{MPa} \cdot \mathrm{m}^{1 / 2}$ (fracture toughness of the $\mathrm{TiB}_{2}-\mathrm{SiC}$ ceramics [31]). The improvement of flexural strength and Vickers hardness is due to the relatively fine microstructure, which is in agreement with the result that the fine microstructure can improve the mechanical properties of ceramic composite materials [32]. As the $\mathrm{HfB}_{2}$ content increases, the fracture toughness decreases gradually, which can be ascribed to the increase of the brittle rim phase. The reason is that the rim phase is mainly the complex solid solution of $\mathrm{TiB}_{2}$ and $\mathrm{HfB}_{2}$, which may be a brittle phase; moreover, the wettability between $\mathrm{HfB}_{2}$ and $\mathrm{Ni}$ (the wettability angle: $\sim 99^{\circ}$ ) is poor.

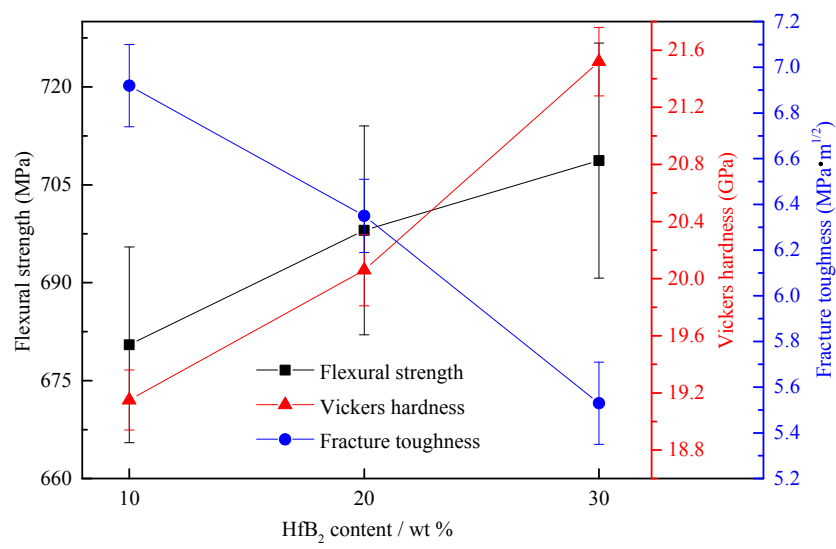

(a)

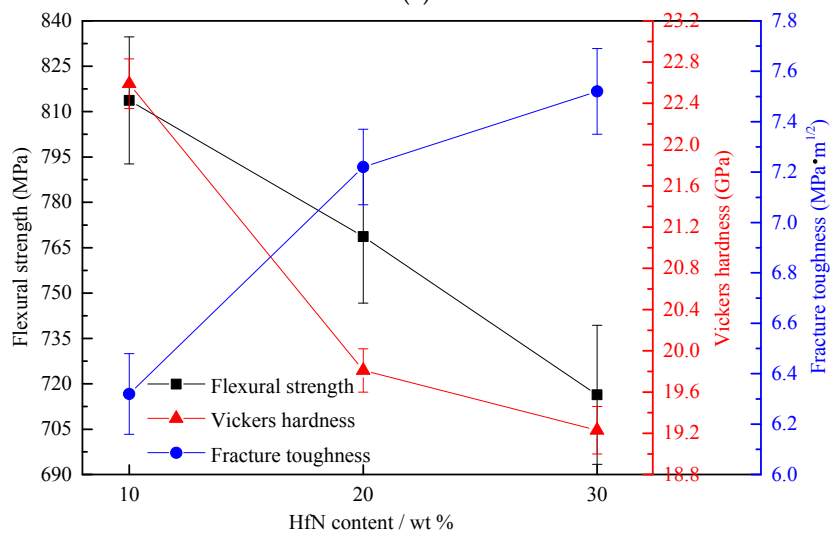

(b)

Figure 6. Variation of the mechanical properties of $\mathrm{TiB}_{2}-\mathrm{HfB}_{2}$ ceramics with a change of the $\mathrm{HfB}_{2}$ content and variation of the mechanical properties of $\mathrm{TiB}_{2}-\mathrm{HfN}$ ceramics with a change of the HfN content.

In Figure $6 \mathrm{~b}$, with the increase of the HfN content from $10 \mathrm{wt} \%$ to $30 \mathrm{wt} \%$, the flexural strength decreases from $813.69 \pm 21 \mathrm{MPa}$ to $716.37 \pm 23 \mathrm{MPa}$; the Vickers hardness decreases from $22.59 \pm 0.24 \mathrm{GPa}$ to $19.23 \pm 0.23 \mathrm{GPa}$; however, the fracture toughness increases from 
$6.32 \pm 0.16 \mathrm{MPa} \cdot \mathrm{m}^{1 / 2}$ to $7.52 \pm 0.17 \mathrm{MPa} \cdot \mathrm{m}^{1 / 2}$. The $\mathrm{TiB}_{2}-10 \mathrm{wt} \% \mathrm{HfN}$ ceramic tool material shows better mechanical properties, including flexural strength of $813.69 \pm 21 \mathrm{MPa}$ that is higher than $705 \mathrm{MPa}$ (flexural strength of the $\mathrm{TiB}_{2}-10$ wt \% SiC ceramics [6]), Vickers hardness of $22.59 \pm 0.24 \mathrm{GPa}$ which is higher than $21.85 \mathrm{GPa}$ (Vickers hardness of the $\mathrm{TiB}_{2}-\mathrm{TiC}-10$ wt \% Ni ceramics [33]), and fracture toughness of $6.32 \pm 0.16 \mathrm{MPa} \cdot \mathrm{m}^{1 / 2}$ that is higher than $6 \mathrm{MPa} \cdot \mathrm{m}^{1 / 2}$ (fracture toughness of the $\mathrm{TiB}_{2}-2.5$ wt \% MoSi ceramics [15]). The decrease of the flexural strength and Vickers hardness is due to the increase of the defects such as the $\mathrm{TiB}_{2}$ coarse grain and HfN agglomeration; this indicates that the defects have more negative effects on the flexural strength and Vickers hardness than the core-rim structure, although the core-rim structure is advantageous for improving the mechanical properties. The enhancement of fracture toughness is mainly attributed to the decrease of the pore number and the increase of the rim phase and $\mathrm{TiB}_{2}$ coarse grain; decreasing the pore formation can keep the cracks from growing, which will improve fracture toughness; the rim phase of $\mathrm{TiB}_{2}-\mathrm{HfN}$ ceramics exhibits a higher grain boundary strength than the rim phase of $\mathrm{TiB}_{2}-\mathrm{HfB}_{2}$ ceramics, which will provide a larger grain growth resistance for enhancing fracture toughness; in addition, $\mathrm{TiB}_{2}$ coarse grains can consume more fracture energy in the fracturing process even though the $\mathrm{TiB}_{2}$ is a brittle phase, which leads to the improvement of the fracture toughness.

In order to further analyze the toughening mechanisms of $\mathrm{TiB}_{2}-\mathrm{HfB}_{2}$ and $\mathrm{TiB}_{2}-\mathrm{HfN}$ ceramics, the crack propagation paths are shown in Figure 7. As can be seen, the crack propagation path in Figure 7a is straighter than that in Figure 7b; the crack deflection in Figure $7 \mathrm{~b}$ is more obvious than that in Figure 7a; crack bridging and transgranular fracture play an important role in Figure 7a, while crack deflection, crack bridging, and transgranular fracture occupy important positions in Figure $7 \mathrm{~b}$, which are advantageous for enhancing fracture toughness and are the main toughening mechanisms of these ceramics. Much fracture energy will be consumed by crack bridging because crack bridging as well as crack deflection can change the direction of crack propagation (see the red circles in Figure 7), which is advantageous for improving fracture toughness. Usually the formation of the rim phase is propitious to the enhancement of fracture toughness, but in Figure 7a the rim phase shows a brittle characteristic leading to lower fracture toughness with increasing $\mathrm{HfB}_{2}$ content as mentioned above; moreover, the relatively straight crack crossing the rim phase and $\mathrm{TiB}_{2}$ grain will consume less fracture energy, which is harmful to the improvement of fracture toughness. However, intergranular fracture and transgranular fracture coexisted in Figure 7b, where the crack path is full of twists and turns which is advantageous to enhancing fracture toughness.

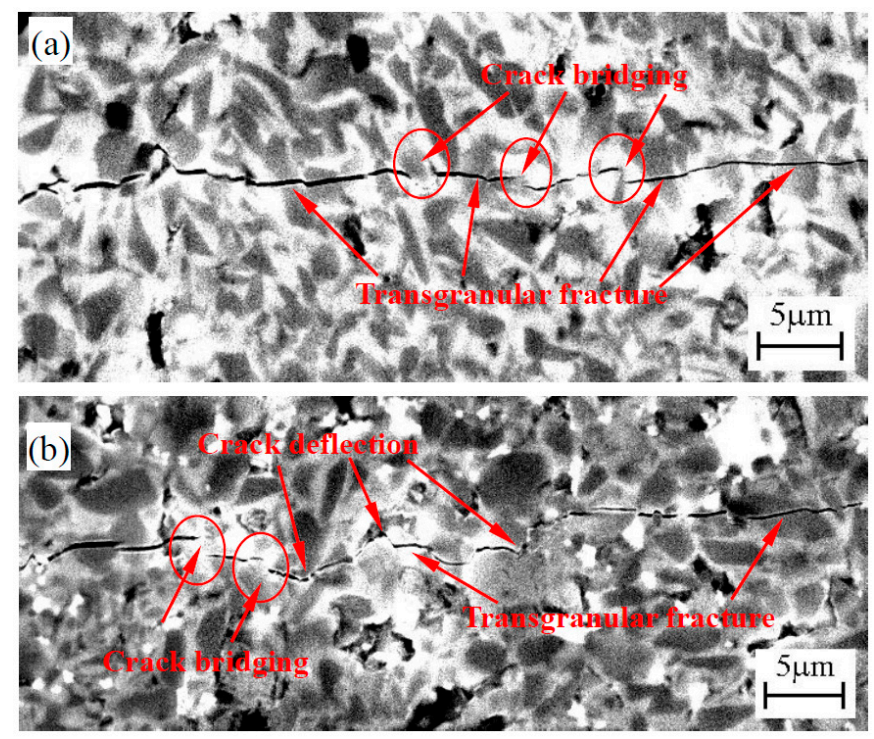

Figure 7. Crack propagation path of the $\mathrm{TiB}_{2}-\mathrm{HfB}_{2}(\mathbf{a})$ and $\mathrm{TiB}_{2}-\mathrm{HfN}(\mathbf{b})$ ceramic tool materials. 


\section{Conclusions}

$\mathrm{TiB}_{2}$-based ceramic tool materials reinforced by $\mathrm{HfB}_{2}$ and $\mathrm{HfN}$ additives have been fabricated by hot pressed sintering. The effects of $\mathrm{HfB}_{2}$ and $\mathrm{HfN}$ additions on their microstructures and mechanical properties were investigated. The results showed that the $\mathrm{HfB}_{2}$ additive can inhibit the $\mathrm{TiB}_{2}$ grain growth and can change the morphology of some of the $\mathrm{TiB}_{2}$ grains from bigger polygons to smaller polygons or longer ovals, which is favorable for the formation of a relatively fine microstructure, while the $\mathrm{HfN}$ additive tends to agglomerate. With increasing $\mathrm{HfB}_{2}$ and $\mathrm{HfN}$ contents from $10 \mathrm{wt} \%$ to $30 \mathrm{wt} \%$, the relative densities of these ceramics increased gradually. The relatively fine microstructure improved the flexural strength and Vickers hardness of the $\mathrm{TiB}_{2}-\mathrm{HfB}_{2}$ ceramics. The poor wettability between $\mathrm{HfB}_{2}$ and $\mathrm{Ni}$ resulted in the formation of weak grain boundary strength and the complex solid solution of $\mathrm{TiB}_{2}-\mathrm{HfB}_{2}$ is a brittle phase, which led to the decrease of fracture toughness of the $\mathrm{TiB}_{2}-\mathrm{HfB}_{2}$ ceramics. The increase of the defects such as the $\mathrm{TiB}_{2}$ coarse grain and $\mathrm{HfN}$ agglomeration resulted in the decrease of the flexural strength and Vickers hardness of the $\mathrm{TiB}_{2}-\mathrm{HfN}$ ceramics; the decrease of the pore number and the increase of the rim phase and $\mathrm{TiB}_{2}$ coarse grain are advantageous for the enhancement of fracture toughness. The toughening mechanisms of the $\mathrm{TiB}_{2}-\mathrm{HfB}_{2}$ ceramics mainly included crack bridging and transgranular fracture, while the toughening mechanisms of the $\mathrm{TiB}_{2}-\mathrm{HfN}$ ceramics mainly included crack deflection, crack bridging, transgranular fracture, and the core-rim structure. The $\mathrm{TiB}_{2}-30 \mathrm{wt} \% \mathrm{HfB}_{2}$ ceramic tool material exhibited better mechanical properties including a flexural strength of $708.71 \pm 18 \mathrm{MPa}$, Vickers hardness of $21.52 \pm 0.24 \mathrm{GPa}$, and fracture toughness of $5.53 \pm 0.18 \mathrm{MPa} \cdot \mathrm{m}^{1 / 2}$. The $\mathrm{TiB}_{2}-10 \mathrm{wt} \% \mathrm{HfN}$ ceramic tool material showed better mechanical properties including a flexural strength of $813.69 \pm 21 \mathrm{MPa}$, Vickers hardness of $22.59 \pm 0.24 \mathrm{GPa}$, and fracture toughness of $6.32 \pm 0.16 \mathrm{MPa} \cdot \mathrm{m}^{1 / 2}$.

Acknowledgments: This project is supported by the National Natural Science Foundation of China (Grant No. 51405326 and Grant No. 51575375) and the Scientific and Technological Innovation Programs of Higher Education Institutions in Shanxi (Grant No. 2014122).

Author Contributions: Jing An, Pengjin Song, and Guoxing Liang conceived and designed the experiments; Jing An, Jiaojiao Gao and Juncai Xie performed the experiments; An Jing and Lei Cao analyzed the data; Jing An and Shiying Wang contributed reagents/materials/analysis tools; Jing An, Pengjin Song, Jiaojiao Gao and Ming Lv wrote the paper.

Conflicts of Interest: The authors declare no conflict of interest.

\section{References}

1. Wang, M.; Zhao, J.; Wang, L.L. Wear behaviour of $\mathrm{Al}_{2} \mathrm{O}_{3} / \mathrm{Ti}(\mathrm{C}, \mathrm{N})$ ceramic tool during turning process of martensitic stainless steel. Mater. Res. Innov. 2015, 19, 350-354. [CrossRef]

2. Zheng, G.M.; Zhao, J.; Zhou, Y.H.; Li, A.H.; Cui, X.B.; Tian, X.H. Performance of graded nano-composite ceramic tools in ultra-high-speed milling of Inconel 718. Int. J. Adv. Manuf. Technol. 2013, 67, 2799-2810. [CrossRef]

3. Wang, D.; Zhao, J.; Cao, Y.; Xue, C.; Bai, Y. Wear behavior of an $\mathrm{Al}_{2} \mathrm{O}_{3}$ /TiC/TiN micro-nano-composite ceramic cutting tool in high-speed turning of ultra-high-strength steel 300 M. Int. J. Adv. Manuf. Technol. 2016, 87, 3301-3306. [CrossRef]

4. Kwon, W.T.; Kim, Y.W. Cutting performance of $\mathrm{Si}_{3} \mathrm{~N}_{4}$ based $\mathrm{SiC}$ ceramic cutting tools. J. Mech. Sci. Technol. 2004, 18, 388-394. [CrossRef]

5. Song, J.P.; Huang, C.Z.; Lv, M.; Zou, B.; Liu, H.L.; Wang, J. Cutting performance and failure mechanisms of $\mathrm{TiB}_{2}$-based ceramic cutting tools in machining hardened $\mathrm{Cr}_{12} \mathrm{MoV}$ mold steel. Int. J. Adv. Manuf. Technol. 2014, 70, 495-500. [CrossRef]

6. Zhao, G.L.; Huang, C.Z.; He, N.; Liu, H.L.; Zou, B. Preparation and cutting performance of reactively hot pressed $\mathrm{TiB}_{2}-\mathrm{SiC}$ ceramic tool when machining Invar36 alloy. Int. J. Adv. Manuf. Technol. 2016, 86, 2679-2688. [CrossRef]

7. Vlasova1, M.; Bykov, A.; Kakazey, M.; Aguilar, P.A.M.; Melnikov, I.; Rosales, I.; Tapia, R.G. Formation and Properties of $\mathrm{TiB}_{2}-\mathrm{Ni}$ Composite Ceramics. Sci. Sinter. 2016, 48, 137-146. [CrossRef] 
8. Lin, J.; Yang, Y.H.; Zhang, H.A.; Chen, W.F.; Huang, Y. Microstructure and mechanical properties of TiB 2 ceramics enhanced by $\mathrm{SiC}$ particles and carbon nanotubes. Ceram. Int. 2016, 42, 4627-4631. [CrossRef]

9. Demirskyi, D.; Nishimura, T.; Sakka, Y.; Vasylkiv, O. High-strength $\mathrm{TiB}_{2}-\mathrm{TaC}$ ceramic composites prepared using reactive spark plasma consolidation. Ceram. Int. 2016, 42, 1298-1306. [CrossRef]

10. Raju, G.B.; Basu, B.; Tak, N.H.; Cho, S.J. Temperature dependent hardness and strength properties of TiB 2 with TiSi 2 sinter-aid. J. Eur. Ceram. Soc. 2009, 29, 2119-2128. [CrossRef]

11. Popov, A.Y.; Sivak, A.A.; Borodianska, H.Y.; Shabalin, I.L. High toughness $\mathrm{TiB}_{2}-\mathrm{Al}_{2} \mathrm{O}_{3}$ composite ceramics produced by reactive hot pressing with fusible components. Adv. Appl. Ceram. 2015, 114, 178-182. [CrossRef]

12. Song, J.P.; Huang, C.Z.; Lv, M.; Zou, B.; Wang, S.Y.; Wang, J.; An, J. Effects of TiC content and melt phase on microstructure and mechanical properties of ternary $\mathrm{TiB}_{2}$-based ceramic cutting tool materials. Mater. Sci. Eng. A 2014, 605, 137-143. [CrossRef]

13. Gao, Y.B.; Tang, T.G.; Yi, C.H.; Zhang, W.; Li, D.C.; Xie, W.B.; Huang, W.; Ye, N. Study of static and dynamic behavior of $\mathrm{TiB}_{2}-\mathrm{B}_{4} \mathrm{C}$ composite. Mater. Des. 2016, 92, 814-822. [CrossRef]

14. Demirskyi, D.; Sakka, Y.; Vasylkiv, O. High-temperature reactive spark plasma consolidation of $\mathrm{TiB}_{2}-\mathrm{NbC}$ ceramic composites. Ceram. Int. 2015, 41, 10828-10834. [CrossRef]

15. Mukhopadhyay, A.; Raju, G.B.; Basu, B.; Suri, A.K. Correlation between phase evolution, mechanical properties and instrumented indentation response of $\mathrm{TiB}_{2}$-based ceramics. J. Eur. Ceram. Soc. 2009, 29, 505-516. [CrossRef]

16. $\mathrm{Li}, \mathrm{B}$. Effect of $\mathrm{ZrB}_{2}$ and $\mathrm{SiC}$ addition on $\mathrm{TiB}_{2}$-based ceramic composites prepared by spark plasma sintering. Int. J. Refract. Met. Hard Mater. 2014, 46, 84-89. [CrossRef]

17. Sonber, J.K.; Murthy, T.S.R.C.; Subramanian, C.; Krishnamurthy, N.; Hubli, R.C.; Suri, A.K. Effect of CrSi 2 and $\mathrm{HfB}_{2}$ addition on densification and properties of $\mathrm{ZrB}_{2}$. Int. J. Refract. Met. Hard Mater. 2012, 31, 125-131. [CrossRef]

18. Balak, Z.; Zakeri, M. Effect of $\mathrm{HfB}_{2}$ on microstructure and mechanical properties of $\mathrm{ZrB}_{2}$-SiC-based composites. Int. J. Refract. Met. Hard Mater. 2016, 54, 127-137. [CrossRef]

19. Tu, R.; Li, N.; Li, Q.Z.; Zhang, S.; Zhang, L.M.; Goto, T. Effect of microstructure on mechanical, electrical and thermal properties of $\mathrm{B}_{4} \mathrm{C}-\mathrm{HfB}_{2}$ composites prepared by arc melting. J. Eur. Ceram. Soc. 2016, 36, 3929-3937. [CrossRef]

20. Wang, S.H.; Zhang, Y.C.; Sun, Y.; Xu, Y.; Yang, M. Synthesis and characteristic of SiBCN/HfN ceramics with high temperature oxidation resistance. J. Alloys Compd. 2016, 685, 828-835. [CrossRef]

21. Li, B.H.; Liu, Y.; Cao, H.; He, L.; Li, J. Rapid synthesis of $\mathrm{TiB}_{2} / \mathrm{Fe}$ composite in situ by spark plasma sintering. J. Mater. Sci. 2009, 44, 3909-3912. [CrossRef]

22. Sáez, A.; Arenas, F.; Vidal, E. Microstructure development of WCoB-TiC based hard materials. Int. J. Refract. Met. Hard Mater. 2003, 21, 13-18. [CrossRef]

23. Zhang, G.; Yang, J.H. In situ synthesis aluminum borate whiskers reinforced $\mathrm{TiB}_{2}$ matrix composites for application in aluminum reduction cells. JOM 2013, 65, 1467-1471. [CrossRef]

24. Farhadi, K.; Namini, A.S.; Asl, M.S.; Mohammadzadeh, A.; Kakroudi, M.G. Characterization of hot pressed $\mathrm{SiC}$ whisker reinforced $\mathrm{TiB}_{2}$ based composites. Int. J. Refract. Met. Hard Mater. 2016, 61, 84-90. [CrossRef]

25. Cui, H.Z.; Zhang, Y.F.; Zhang, G.S.; Liu, W.; Song, X.J.; Wei, N. Pore and microstructure change induced by $\mathrm{SiC}$ whiskers and particles in porous $\mathrm{TiB}_{2}-\mathrm{TiC}_{-} \mathrm{Ti}_{3} \mathrm{SiC}_{2}$ composites. Ceram. Int. 2016, 42, 8376-8384. [CrossRef]

26. China State Bureau of Technological Supervision. Chinese National Standards_Fine Ceramics (Advanced Ceramics, Advanced Technical Ceramics)—Test Method for Flexural Strength of Monolithic Ceramics at Room Temperature; Chinese Standard Publishing House: Beijing, China, 2006.

27. Zhao, G.L.; Huang, C.Z.; He, N.; Liu, H.L.; Zou, B. Microstructure and mechanical properties at room and elevated temperatures of reactively hot pressed $\mathrm{TiB}_{2}-\mathrm{TiC}-\mathrm{SiC}$ composite ceramic tool materials. Ceram. Int. 2016, 42, 5353-5361. [CrossRef]

28. China State Bureau of Technological Supervision. Chinese National Standards_Fine Ceramics (Advanced Ceramics, Advanced Technical Ceramics)—Test Method for Flexural Strength of Monolithic Ceramics at Room Temperature; Chinese Standard Publishing House: Beijing, China, 2009.

29. Khalfallah, I.; Aning, A. Bulk Processing and Mechanical Properties of $\mathrm{Ni}_{3} \mathrm{Mo}$. In Proceedings of the 143rd TMS Annual Meeting \& Exhibition, San Diego, CA, USA, 16-20 February 2014; pp. 999-1006. 
30. Qi, L.; Jin, Y.C.; Zhao, Y.H.; Yang, X.M.; Zhao, H.; Han, P. The structural, elastic, electronic properties and Debye temperature of $\mathrm{Ni}_{3} \mathrm{Mo}$ under pressure from first-principles. J. Alloys Compd. 2015, 621, 383-388. [CrossRef]

31. Chen, H.B.; Wang, Z.; Wu, Z.J. Investigation and characterization of densification, processing and mechanical properties of $\mathrm{TiB}_{2}-\mathrm{SiC}$ ceramics. Mater. Des. 2014, 64, 9-14. [CrossRef]

32. Anggraini, L.; Isonishi, K.; Ameyama, K. Toughening and strengthening of ceramics composite through microstructural refinement. Am. Inst. Phys. 2016, 1725, 1-5.

33. Fu, Z.Z.; Koc, R. Sintering and mechanical properties of $\mathrm{TiB}_{2}-\mathrm{TiC}-\mathrm{Ni}$ using submicron borides and carbides. Mater. Sci. Eng. A 2016, 676, 278-288. [CrossRef]

(C) 2017 by the authors. Licensee MDPI, Basel, Switzerland. This article is an open access article distributed under the terms and conditions of the Creative Commons Attribution (CC BY) license (http:/ / creativecommons.org/licenses/by/4.0/). 